(C) Elsevier Scientific Publishing Company, Amsterdam - Printed in The Netherlands

\title{
A SPATIAL MODEL OF GROWTH AND COMPETITION STRATEGIES IN CORAL COMMUNITIES
}

\author{
LYNN A. MAGUIRE * and JAMES W. PORTER ** \\ * Environmental Sciences Division, Oak Ridge National Laboratory ${ }^{\dagger}$, Oak Ridge, Tenn. \\ 37830 (U.S.A.) \\ ** School of Natural Resources, University of Michigan, Ann Arbor, Mich. 48109 (U.S.A.) \\ * Present address : Department of Wildlife Science, UMC 52, Utah State University, \\ Logan, Utah 84322 (U.S.A.) \\ Publication No. 1032, Environmental Sciences Division, Oak Ridge National Laboratory
}

(Received 23 July 1976; revised 22 January 1977)

\begin{abstract}
Maguire, L.A. and Porter, J.W., 1977. A spatial model of growth and competition strategies in coral communities. Ecol. Modelling, 3: 249-271.
\end{abstract}

A discrete spatial simulation model is developed to investigate the type and intensity of biological and physical factors influencing the structure of coral communities. The model represents reproduction, growth, and interspecific competition by coral colonies in terms of "ownership" of space in a plot of reef habitat. Using data for several eastern Pacific coral species, the model reproduces observed changes in species composition and diversity during coral community development. Model results suggest that during early successional stages, or in areas that are frequently disturbed, larval colonization and rapid growth are more important than dominance achieved by extracoelenteric digestion or by growing over another coral in acquiring and maintaining possession of reef substrate. In mature communities that remain undisturbed, dominance is the best competitive strategy. Although the model was developed to study natural and man-induced changes in the community dynamics of coral reefs, it could be adapted to study other sessile organisms where spatial pattern is an important influence on the frequency and outcome of biological interactions.

\section{INTRODUCTION}

Recent studies in benthic ecology have focused on the interplay between competition and predation (biological disturbance) in controlling community structure (Connell, 1971; Dayton, 1971; Dayton and Hessler, 1972; Grassle and Sanders, 1973; Levin and Paine, 1974; Porter, 1974a). The influence of reproductive rate and timing in the development of non-equilibrium or successional stages of marine communities has also been considered (Levinton, 1970; Reiswig, 1973; Rhoads, 1973; Sutherland, 1974; Grassle

† Operated by Union Carbide Corporation under contract with the Energy Research and Development Administration. 
and Grassle, 1974). Porter (1974a) and Grigg and Maragos (1974) describe contrasting patterns of coral community structure in different geographical areas and suggest contrasting biological and physical mechanisms to account for the differences. This paper describes the construction and preliminary analysis of a simulation model designed to investigate how various types of coral community structure arise and are biologically and physically maintained. The paper briefly reviews the relevant aspects of coral ecology, describes the structure and assumptions of the model, and then discusses the results of simulations and their implications for understanding the development of coral communities.

\section{CORAL ECOLOGY}

Adult corals are sessile, but they reproduce by means of mobile planktonic larvae. Huge numbers of propagules are broadcast, but only a few settle successfully and begin to grow. Corals grow at species-characteristic rates. Most grow approximately radially, although there are many variations on a basically circular growth form, e.g., branching, lobes, spheres, and cones (Barnes, 1973) (Fig. 1). Corals compete for space, both to capture zooplankton for food and to provide light for symbiotic algae. Competitive strategies among coral species include (1) overtopping, much as plants shade out and kill neighboring individuals (Porter, 1974a), and (2) digestive dominance, where a more dominant species digests contiguous portions of less aggressive corals and grows over them (Lang, 1973) (Fig. 2). Since the effect of an overtopping morphology is identical to that of a high position on the digestive dominance hierarchy, that is, space is successfully captured, these two parameters may be summed into an overall dominance rating which is the net result of these two space capture mechanisms (Table I). The outcome of interspecific competition among sympatric coral species is remarkably consistent over a range of physical conditions (Lang, 1973; Porter, 1974a; Glynn, 1974; field observations, JWP). In some areas in the Pacific, corals are subject to heavy predation by the crown-of-thorns starfish, Acanthaster planci, and other vertebrate and invertebrate corallivores (Glynn et al., 1972; Porter, 1974a). Physical disturbances, such as hurricanes, tides, surf, lava flows, and sedimentation, also influence coral reef development (Stoddart, 1969; Grigg and Maragos, 1974) (Fig. 3).

Observations of coral community structure on Hawaiian (Grigg and Maragos, 1974), eastern Pacific (Porter, 1972a, 1974a), and Caribbean (Porter, $1972 \mathrm{~b}, 1974 \mathrm{a}$ ) reefs show consistently different relationships among coral cover, diversity, physical disturbance, predation, and interspecific competition in the three areas. In the eastern Pacific, there is a negative correlation between area covered by live coral and species diversity (Fig. 4). [Species diversity is measured according to the Shannon formula (Pielou, 1966):

$H^{\prime}=-\sum_{i=1}^{n} p_{i} \log _{2} p_{i}$ 

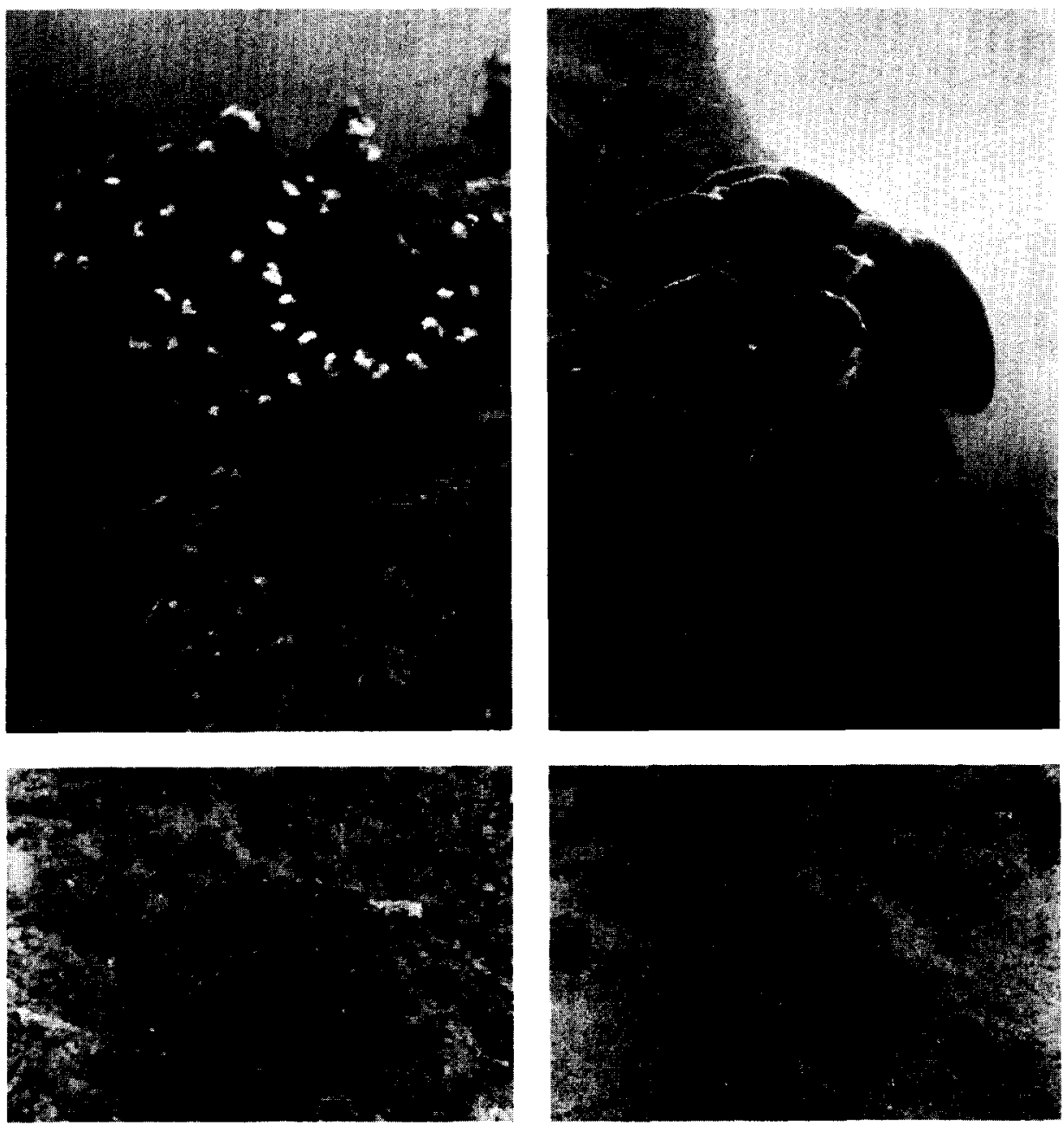

Fig. 1. Eastern Pacific reef corals, Pocillopora damicornis (left top and bottom), Pavona clivosa (right top), and Pavona gigantea (right bottom), colonize stable (top) and unstable (bottom) substrates. These coral colonies probably originated from the successful settlement and growth of larvae. Note the broken tips and nibbled edges from puffer fish, trigger fish, and parrot fish bites. Top left and right: Isla Naranja, 21 March 1971, $5 \mathrm{~m}$ depth; bottom left and right: Islas Secas, 24 March 1971, $3 \mathrm{~m}$.

where $p_{i}=$ relative abundance of the $i$ th coral species expressed as a fraction of the total area covered by corals.] Where rates of disturbance are high, coral cover is low but coral species diversity is high because less dominant species can persist without interference from the more aggressive species (Porter, 1974a; Loya, 1976).

Along the Caribbean coast of Panama, there is a positive correlation between coral cover and diversity (Porter, 1972b, 1974a). Among species 

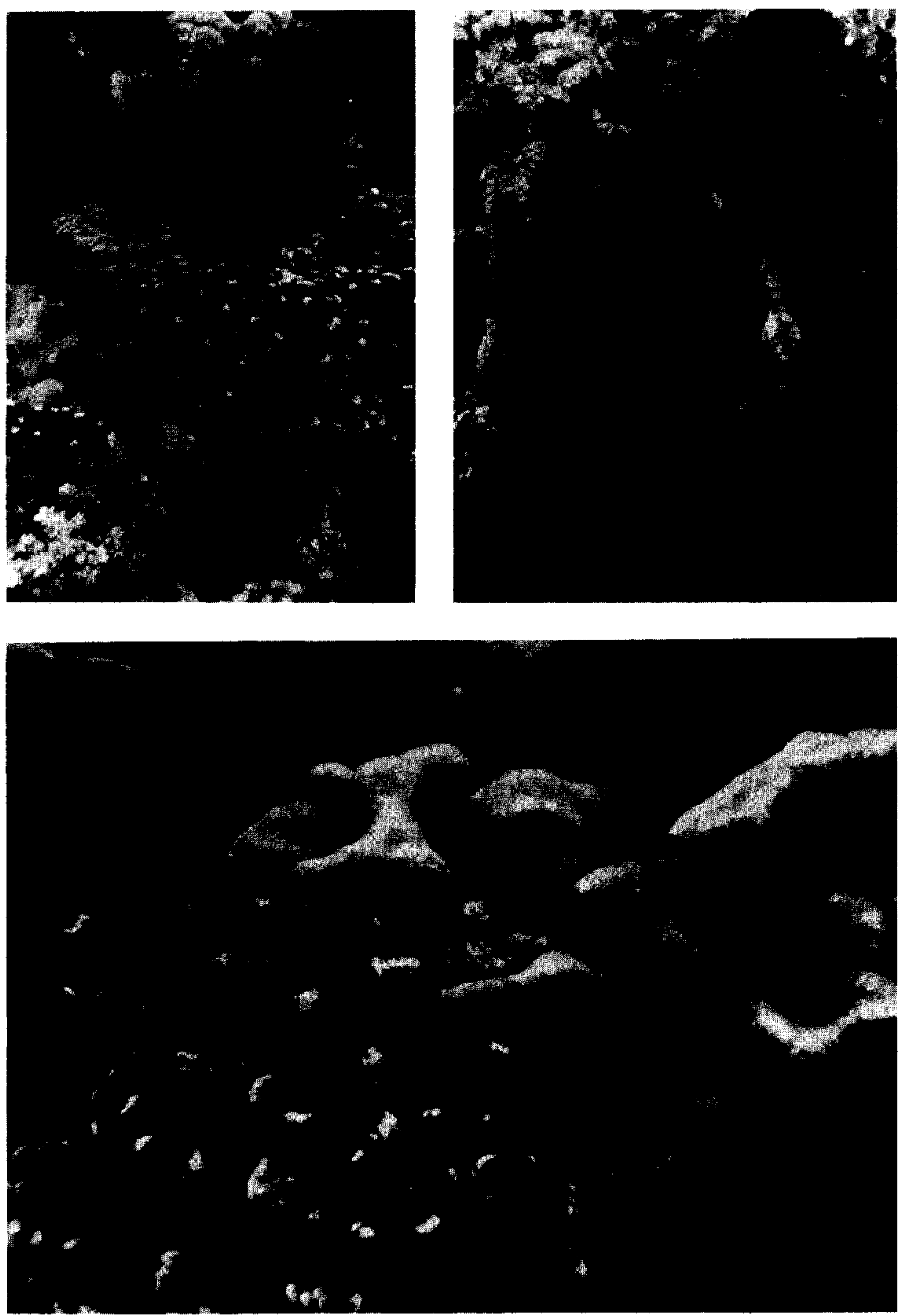

Fig. 2. Eastern Pacific reef corals compete for space by over-topping (top left and bottom, Pocillopora damicornis > Pavona clivosa) and by "digestive dominance" where the dominant species kills the physically adjacent coral and overgrows its dead skeleton (top right, Pavona varians scales the side of Pavona clivosa; note also the dead areas of Pavona clivosa adjacent to the branches of Pocillopora in the center of the upper left figure). As in Fig. 1, note the extensive fish nips and scrapes. Top left: Islas Secas, 24 March 1971, $4 \mathrm{~m}$ depth; top right: Isla Uva, 23 March 1971, $3 \mathrm{~m}$; bottom: Isla Naranja, 21 March 1971 $6 \mathrm{~m}$. 


\section{TABLE I}

Data for eastern Pacific coral species in model

\begin{tabular}{llll}
\hline Species name & Species number & Dominance * & $\begin{array}{l}\text { Radial growth rate ** } \\
\text { (cm/year) }\end{array}$ \\
\hline Pocillopora damicornis & 6 & High & 10 \\
Pocillopora robusta & 5 & & 5 \\
Pavona gigantea & 4 & & 2 \\
Pavona clivosa & 3 & $\downarrow$ & 2.5 \\
Porites panamensis & 2 & Low & 1 \\
Psammocora stellata & 1 & 1 \\
\hline
\end{tabular}

* Dominance is the net result of space-capture abilities due to an overtopping morphology and/or to a high position on the digestive dominance hierarchy. Positions are assigned here based on laboratory and field data from Porter (1974a) and Glynn (1974) and personal observations (JWP).

** Radial growth rate is for optimal conditions without predation or other disturbances.
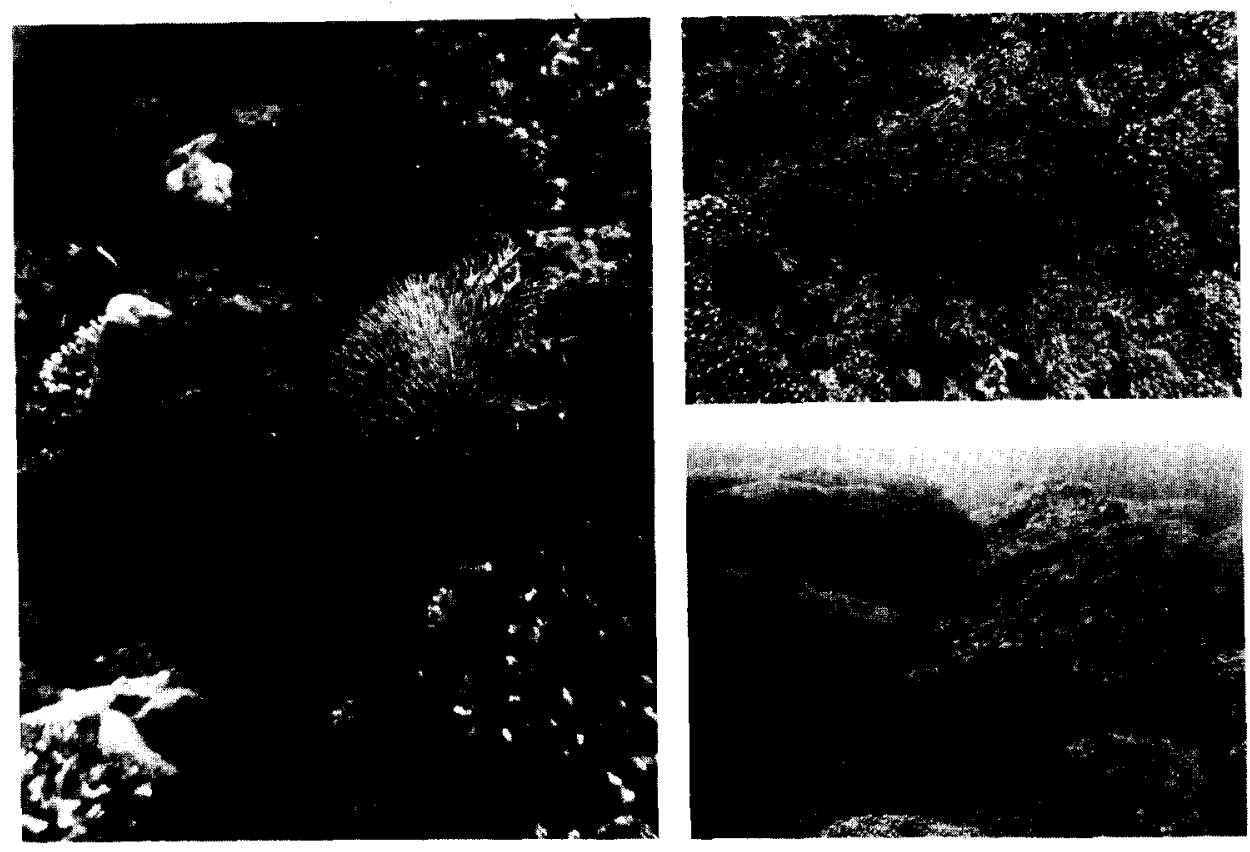

Fig. 3. Biological events, such as predation (left, Acanthaster planci attacking eastern Pacific Pocillopora damicornis and Pavona ponderosa), and physical disturbances, such as storm damage (top right, toppled Pocillopora) or collapse (bottom right, Pocillopora reef caved in), can play a major role in the production of new sites for colonization. Numerous organisms in addition to corals will compete for these settling places. Left: Isla Uva, 23 March 1971, $2 \mathrm{~m}$; top right: Isla Uva, 23 March 1971, $3 \mathrm{~m}$; bottom right: Islas Secas, 24 March $1971.3 \mathrm{~m}$. 

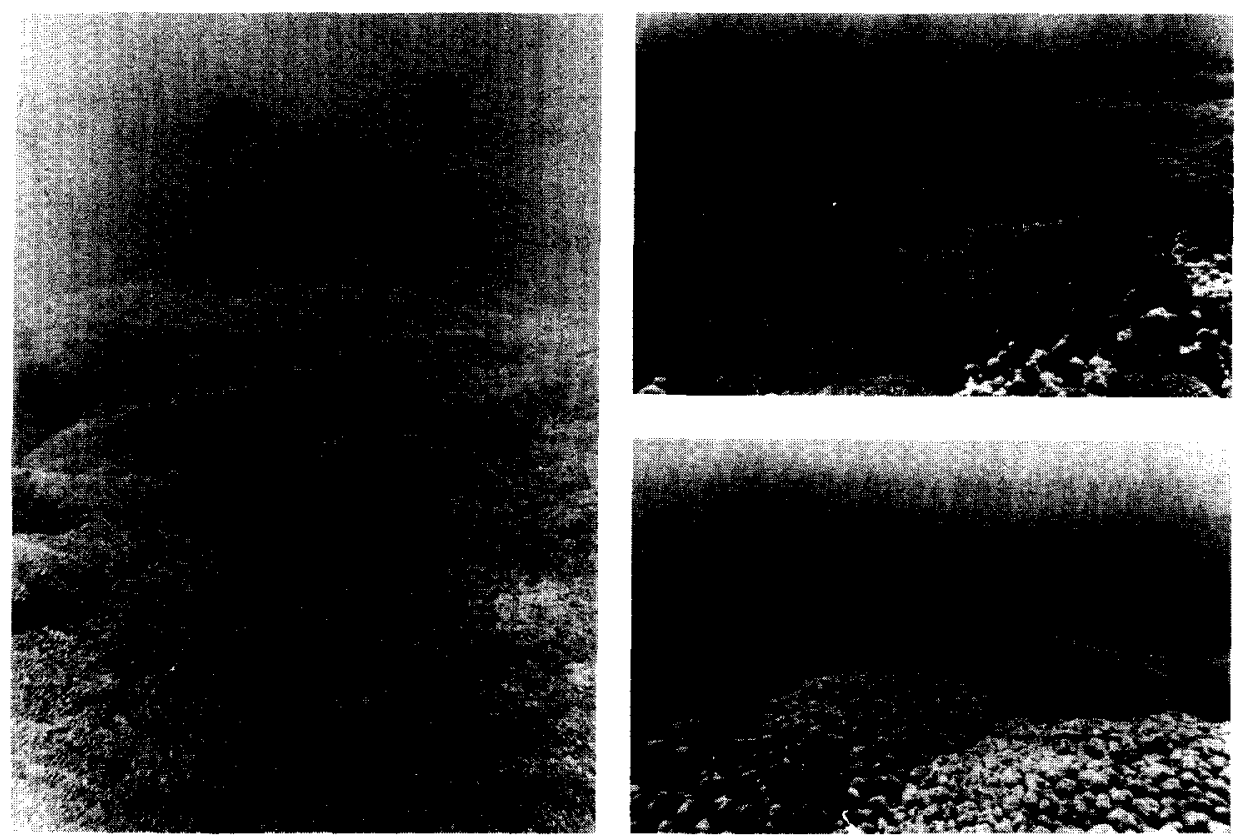

Fig. 4. With a minimum of disturbance (physical or biological) to reset the successional development, most shallow-water eastern Pacific coral communities tend toward the condition illustrated by the Pocillopora reef on the left. Stages in such a development pattern would include earlier periods of higher diversity and lower cover (top right and bottom right) before competitive exclusion reduced the diversity to a monospecific stand of the dominant coral (left). Left: Islas Secas, 24 March 1971, $3 \mathrm{~m}$; top right: Islas Secas, 24 March 1971, $3.5 \mathrm{~m}$; bottom right; Islas Secas, 24 March 1971, $3.5 \mathrm{~m}$.

from this area, the fastest-growing are the weakest competitors in terms of digestive dominance. It has been suggested (Porter, 1974a) that the lack of clear-cut competitive superiority in a single Caribbean species retards development of the monospecific stands that are common on eastern Pacific reefs.

Off the Hawaiian coast, lava flows periodically destroy sections of coral reefs. Grigg and Maragos (1974) observed the rates at which reefs in sheltered and unsheltered waters recover to their predisturbance condition. They found a negative correlation between coral cover and diversity and suggested that in sheltered areas, a competitively dominant species monopolizes more and more area as coral cover increases. In less sheltered waters, wave action continually destroys corals, keeping cover low and diversity high.

In summary, major factors influencing community structure and development are: (1) coral reproductive strategies; (2) colony growth rates; (3) competitive dominance relationships; (4) predation; and (5) physical disturbance, such as storms. The model investigates observed features of coral community structure, such as the relationships between coral cover and species diversity. Thus far, effects of coral reproductive strategies, growth, and competitive 
dominance have been studied using the model. Predation (biological disturbance) and storms (physical disturbance) will be examined later.

\section{THE MODEL}

The model represents coral community development in a $25 \mathrm{~m}^{2}$ plot randomly located in a homogeneous reef habitat. The modeled plot is covered by a rectangular grid of points (Fig. 5 shows a section of the plot), and the model keeps track of which coral species "owns" each point. The model has been implemented to represent reproduction, growth, and competition among the six major coral species that may be expected to occur sympatrically on eastern Pacific reefs. Species names, estimated maximum growth rates, and probable dominance relationships are summarized in Table I.

\section{Reproduction}

In the model, we assume that all six coral species reproduce at the same time twice a year. In actuality, reproductive patterns are highly variable from

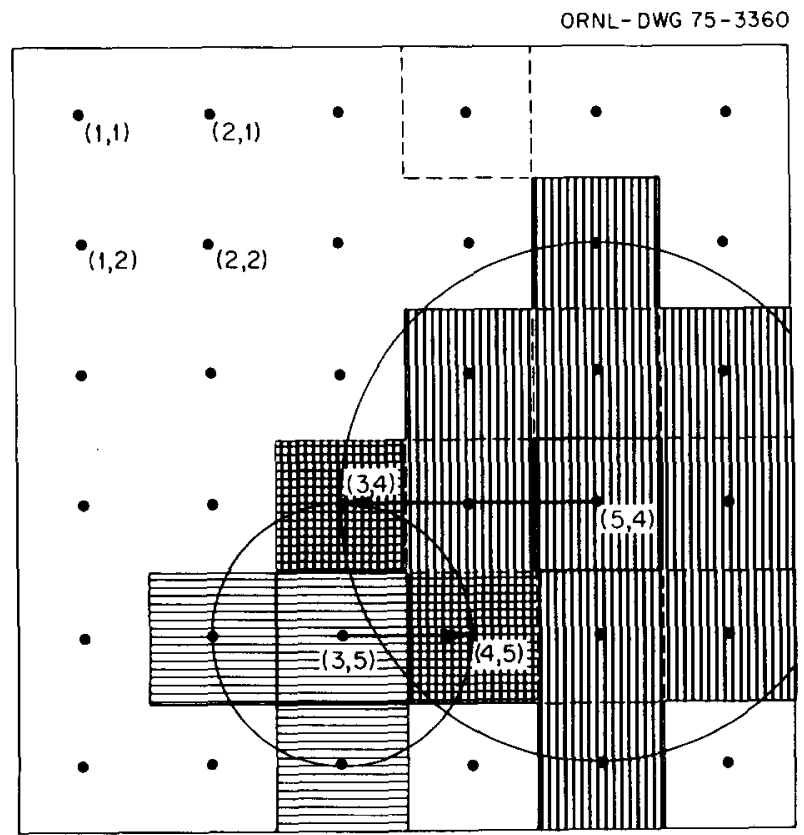

Fig. 5. Diagram of system of grid points on a portion of the modeled plot. Heavy vertical hatching represents area occupied by a coral of species 2 centered at $(5,4)$; lighter horizontal hatching represents area potentially occupied by coral of species 1 centered at $(3,5)$. The more dominant species (defined in text), species 2 , destroys species 1 in the disputed squares $(3,4)$ and $(4,5)$. 
species to species. No species is known to reproduce less than once per year after maturity is reached, but bi-annual and even monthly spawning have been described (Harrigan, 1972). The model presently assumes synchronous breeding of all species, but asynchronous breeding schedules could also be used.

The reproductive rate for each species is defined in terms of successful larval production, i.e., the number of larvae of each species that could settle and begin to grow in an empty plot. Thus, successful larval production would be evaluated after mortality occurring in the planktonic phase of larval life, but before mortality of young corals due to competition or predation on the sessile form. Better data on the mortality patterns of planktonic and newly settled coral larvae would be helpful here.

As a first approximation, we assume that successful larval production for a given species is independent of the area of the plot already covered by that species. The plot is empty at the beginning of the simulation and the initial colonizing larvae are assumed to be carried in from other reefs by ocean currents. Most authors feel that coral larvae settle within the first several days after release (see Connell, 1973, for review), with a maximum time in the plankton of 2 weeks. Assuming normal currents passing over a reef at 0.1 to $0.5 \mathrm{knots}$, the dispersal range of larvae could be 0 to $300 \mathrm{~km}$, depending on the duration of the planktonic stage. Eastern Pacific and Hawaiian corals show very close taxonomic affinities to their Indo-Pacific congeners and are, therefore, probably long dispersers capable of several months' survival in the plankton. Due to the constant, vigorous movement of water in the vicinity of reefs, it seems likely that larvae settling in the model's $25 \mathrm{~m}^{2}$ plot are produced by corals established elsewhere as well as by ones established within the plot. Thus our assumptions are fairly realistic for species having large numbers of widely dispersing propagules, as many benthic organisms do. Alternative assumptions were tested in the model and the results are described below.

Initially, all six species were given the same successful larval production three larvae $/ 25 \mathrm{~m}^{2} /$ reproductive season. Successful larval production by coral species with extensive three-dimensional structures, such as branching corals, will be somewhat underestimated by our two-dimensional approximation. The effect of differential success in larval production due to differences in reproductive potential or colonizing ability among different species will be discussed later.

When reproduction is simulated in the model, a pseudorandom number generator specifies the coordinates of a grid point for each available larva. If the point is already occupied by an established coral, the larva is eaten. If the point is unoccupied, the larva settles and begins to grow. The process is repeated until all propagules for all six species have either settled or been eaten. 


\section{Growth}

We assume that coral growth can be approximated in two dimensions as a constant increase in radius. At each iteration of the model, a constant length $D R_{i}$ is added to the radius of each coral of species $i$ in the plot. In Fig. 5, which shows a small portion of the grid, a larva of species 1 settled at point $(3,5)$. During the next iteration, it grew by an amount $D R_{1}=1.0$, in units of the distance between grid points.

\section{Competition}

In the model, each coral potentially owns all the grid points falling within its radius. When two corals potentially own the same point [for example, $(3,4)$ and $(4,5)$ in Fig. 5], the conflict is resolved on the basis of competitive dominance. If two corals of different species are involved, the more dominant species takes the point. In Fig. 5, species 2 is dominant and would claim both disputed points. It removes the less dominant species from the immediate area by digestion or by overtopping (Fig. 2). In terms of the model, the effects of both competitive mechanisms are identical. If the two corals are of the same species, either may be regarded as owning the point since corals of the same species fuse or stop growing in an area of contact (Lang, 1973). Corals that have been completely grown over by more dominant species, and thus own no points, are considered dead and are removed from the plot.

\section{Coral cover, relative abundance, and diversity}

In the model, "ownership" of one grid point represents cover of a square area equal to the square of the distance between grid points. Total coral cover in the plot is calculated as the percentage of the total number of points in the plot that are owned by corals of any species. The relative abundance of species $i$ is the percentage of total points owned by corals of all species that are owned by species $i$. Diversity is calculated from the formula cited above, where $p_{i}$ is relative abundance expressed as a fraction, rather than as a percentage.

\section{Output}

Sample results from a model run using the original estimates for successful larval production and growth rates appear in Fig. 6; model output is graphed at 2-year intervals. As observed for an undisturbed eastern Pacific reef, coral cover increases (Fig. 6a), the relative abundance of the most dominant species (species 6) increases (Fig. 6b), and diversity decreases (Fig. 6c) with time until an "equilibrium" is reached with the most dominant species occupying the entire plot. Old, undisturbed eastern Pacific reefs are monopolized 
by the competitively dominant Pocillopora (Porter, 1974a) (Fig. 4). In eight model runs, the average time to equilibrium was 17 years. This result agrees with our intuition regarding the speed of succession in coral communities. Endean (1973) suggests a development time of 20-40 years for Australian reefs recovering from starfish infestations.

\section{Grid size and time step}

The model makes a discrete approximation to continuous growth and competition using partial difference equations in one time dimension and two spatial dimensions. As long as the coral growth function is strictly linear, i.e., a constant addition to the radius at each iteration, length of the time step chosen to run the model has no effect on the accuracy of the solution. If coral growth rates are changing continuously through time, e.g., as functions of colony size, density, or depth, then shorter time steps would give more accurate solutions.
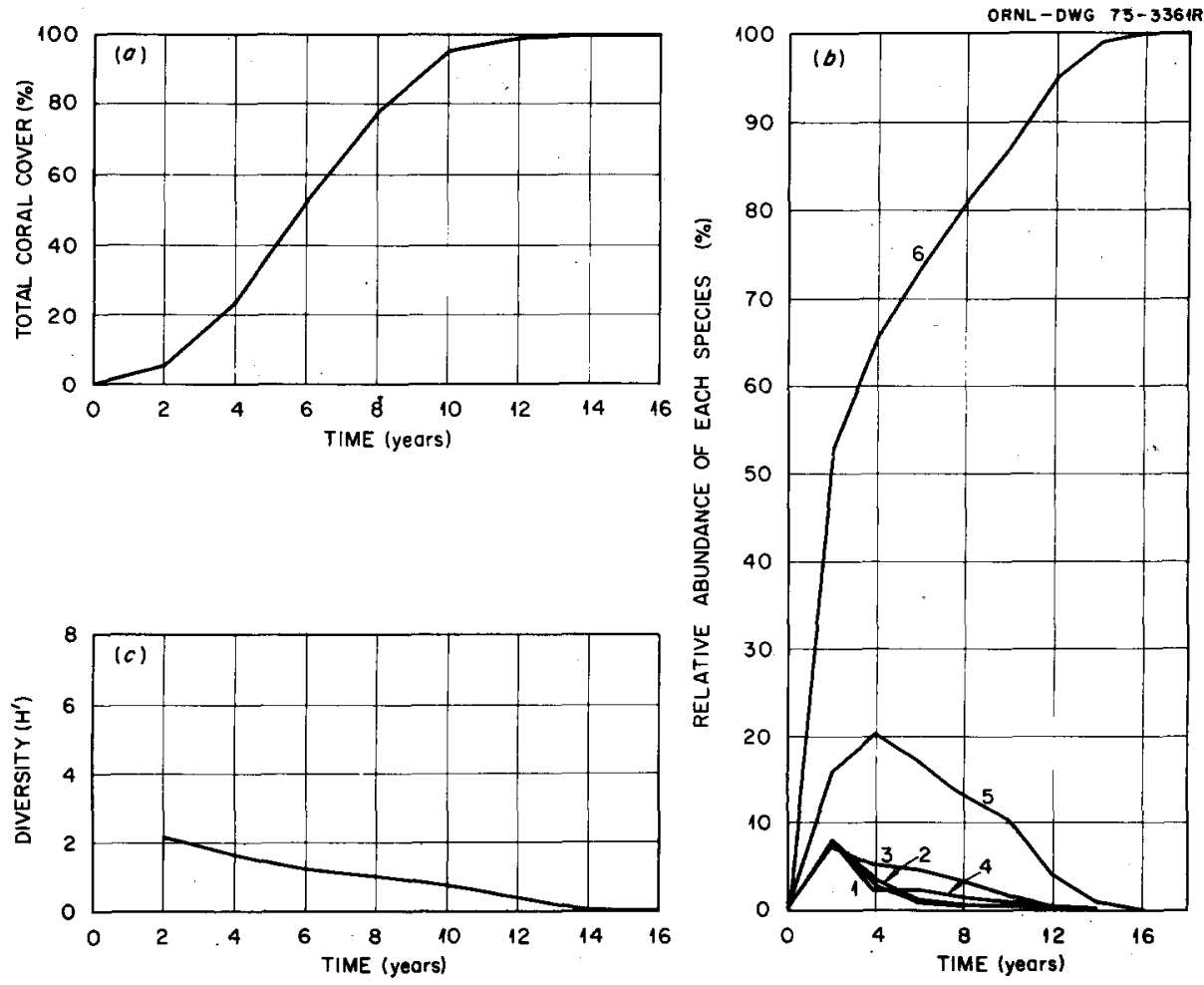

Fig. 6. Model output for original estimates of successful larval production and growth rate: (a) total coral cover versus time; (b) relative abundance of species 1 through 6 versu time; and (c) diversity (defined in text) versus time. 
The effect of changing the distance between points on the spatial grid was tested using distances of $1,2,5,10$ and $20 \mathrm{~cm}$. There were no significant differences at $\alpha=0.01$ among the model results obtained for the different distances because the ratio of occupied to unoccupied points stays the same over the range of distances tested. Insensitivity to time step and grid size are desirable features of the model because they allow the user to choose grid sizes and time steps that are computationally efficient without affecting the accuracy of the solution. Most of the subsequent analyses were performed using $10 \mathrm{~cm}$ distance between points.

\section{Order of reproduction}

Ross and Harper (1972) have pointed out that in plants order of seedling establishment can influence final stand composition through both interspecific and intraspecific competition at the seedling stage. In the original formulation of the model, larvae of species 1 (least dominant) had the first opportunity to become established at each reproductive season, then larvae of species 2 , and so on. To test whether the order in which larvae of different species were permitted to settle influenced model behavior, three alternatives to the original order of reproduction were also used. None made a significant difference in the model results so the original formulation proved acceptable.

\section{SIMULATION RESULTS}

The model behavior shown in Fig. 6 demonstrates that the model produces a realistic simulation of coral community development on undisturbed eastern Pacific reefs (Fig. 4). The analyses of time step, grid size, and order of reproduction indicate that technical problems in the model formulation are not biasing our results. We can, therefore, use the model as a framework for stating hypotheses about factors that influence coral communities, and for projecting the consequences of these hypotheses in terms of patterns of coral community development.

Because no single number characterizes the model output, three aspects of the solution were chosen for comparison: (1) total coral cover after 6 or 10 years; (2) relative abundance of the most dominant species (species 6 ) after 6 or 10 years; and (3) number of years to reach equilibrium.

Use of a pseudorandom number generator to produce the spatial distribution of corals in the plot results in stochastic variation in model output. To compare model behavior for different hypotheses, several replicates were run for each set of parameter values and statistical comparisons were made (Hunter and Naylor, 1970). Percentage data were transformed according to the recommendations in Steele and Torrie (1960, pp. 156-158), and simple linear regression or one-way analysis of variance was used to test for significant effects of the hypothesis being tested on model output. In cases where 
the analysis of variance indicated significant effects, Duncan's new multiple range procedure was used to determine which of several alternatives were significantly different from each other. Although sample sizes were small (three to nine), there were no borderline decisions at $\alpha=0.01$, so the results are considered statistically reliable. In every test, the effect of the independent variable was either significant for all three aspects of the solution described above or not significant for all three.

\section{Colonization strategy}

There would appear to be a biologically defined lower limit to distance between grid points, a minimum area that can be considered available for colonization by a coral larva. The model can be used to examine the consequences of two colonization strategies that could produce a minimum area for colonization. One possibility is that larvae settle passively on a random spot, and then suffer high mortality through competition or predation (Stimson, 1974; Schuhmacher, 1974) if they are too close to an already established coral. It is known (Porter, 1974b) that some species of coral can eat larvae of other coral species. (It is not known at this time whether or not they accidentally eat larvae of their own species.) Alternatively, larvae might actively choose where to settle, responding to factors such as light or type of substrate (Harrigan, 1972; Stimson, 1974; Lewis, 1974) in a way that tends to keep them from settling near established corals. Evidence exists in the literature both for nonrandom underdispersion of coral larvae (Lewis, 1974), where it is hypothesized that the larvae tend to settle near the parent; and for nonrandom overdispersion (Stimson, 1974), where it is hypothesized that predatory activity of epibiotic crustaceans is increased near the parent, thus causing greater survivorship away from the parent. This latter pattern is similar to predation models currently being developed for seed dispersion (Janzen, 1971). Either of the observed dispersion patterns could be produced by either active or passive larval settling strategies, and both strategies would be characterized by a minimum area for successful colonization. Active choice of the settling site based on cues that would differentiate suitable from unsuitable sites would appear to be more adaptive. The passive strategy would bring about a decline in successful colonization as soon as there was a significant probability that a randomly selected point in the plot would be occupied, whereas the active strategy would not produce a decline in successful colonization until all points were occupied. Therefore, we would expect the approach to equilibrium to be faster under the active colonization strategy. We would also expect species with an active larval settling strategy to have at least a short-term advantage over those that settle passively. Simulations showed that the active strategy does produce a significantly shorter time to equilibrium. This is clearly an area where research on the larval biology of each species is greatly needed. 


\section{Successful larval production: some alternatives}

The original assumption for the model was that successful larval production for species $i$ (as defined above) is independent of the area of the plot covered by species $i$ (Fig. 7, curve a). If species $i$ were not represented in the plot, its larvae would nevertheless be carried in by ocean currents; with very few larvae surviving from those shed, compensatory mechanisms rould easily make the total number produced in the plot irrelevant to successful larval production.

Three alternative assumptions, in which successful larval production by species $i$ is a function of area in the $25 \mathrm{~m}^{2}$ plot covered by corals of species $i$, have been tested. The first is a linear function (Fig. 7, curve b), with successful larval production by the $i$ th species $\left(S_{i}\right)$ directly proportional to the area in the plot covered by corals of the $i$ th species $\left(A_{i}\right)$. We assume that each species will attain the original estimate of successful larval production $\left(N_{i}=\right.$ 3 larvae $/ 25 \mathrm{~m}^{2}$ ) when it occupies one-sixth of the plot. Maximum successful larval production for each species (when it occupies the whole plot) is then $6 N_{i}$. The equation for successful larval production by species $i$ as a function of area of the plot covered by species $i$ is then

$S_{i}=6 N_{i} A_{i} / T$

where $T$ equals the area of the whole plot.

The second alternative tested is that successful larval production by species $i$ is a Michaelis-Menten function of the area in the plot covered by corals of species $i$. The equation is fitted so that the original estimate for successful

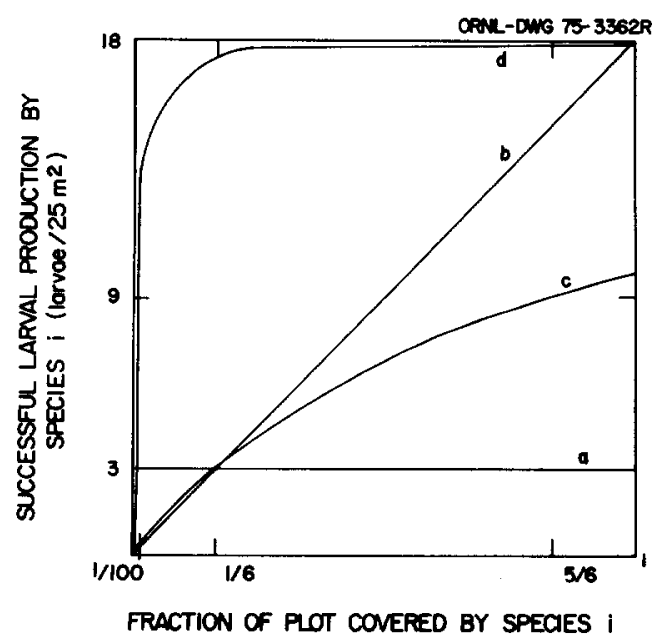

Fig. 7. Four functions relating successful larval production for species $i$ to fraction of the plot covered by species $i$ : (a) constant; (b) linear; (c) Michaelis-Menten function, equation 2 in text; (d) Michaelis-Menten function, equation 3 in text. 
larval production will be reached when a species occupies one-sixth of the plot (Fig. 7, curve c). In this case

$S_{i}=6 N_{i} A_{i} /\left(\frac{5}{6} T+A_{i}\right)$

The third alternative is also a Michaelis-Menten function. However, in this case the equation is fitted to the assumption that successful larval production is at $99 \%$ of its maximum value of $6 N_{i}$ when species $i$ occupies the whole plot (Fig. 7, curve d):

$S_{i}=6 N_{i} A_{i} /\left(\frac{1}{100} T+A_{i}\right)$

For each of the three alternatives, we assume that $S_{i}$ equals one larva when $A_{i}$ equals zero; otherwise, an empty plot would remain empty forever.

The original assumption, successful larval production independent of area covered (curve a), and the first two alternatives (curves $b$ and $c$ ) produce essentially the same results - the plot reaches equilibrium in an average of $17-19$ years. The third alternative (curve d) significantly accelerates the development of the plot - it reaches equilibrium in an average of 12 years.

The results suggest that larval production and colonization strategies are important only in the early stages of coral community development, while the plot is relatively bare. Distinguishing between alternative assumptions regarding successful larval production as a function of area covered is important only for functions that respond sharply to changes in $A_{i}$ in the lower range of $A_{i}$ values (such as Fig. 7, curve d). After 8 to 10 years, when the plot is $90 \%$ covered (Fig. 6a), the behavior of the model is entirely dominated by the growth and competition of established corals. Williams (1975) and others have hypothesized that in many species with both sexual and asexual reproduction, sexual reproduction is most important in colonizing new habitats, whereas asexual reproduction is most important in already occupied habitats. This hypothesis seems very plausible for colonial corals. Larval production (sexual reproduction) is most important for dispersal to and colonization of new or recently disturbed reef areas, but growth of established coral colonies (asexual reproduction) is most important for maintaining a coral species in more mature reefs. Loya's (1976) observations on the recolonization of Red Sea reefs damaged by an unusually low tide support this hypothesis.

\section{Sensitivity to rates of successful larval production and rate of growth}

Simulations were made using values for successful larval production ranging from one-third to ten times the original estimate of 3 larvae $/ 25 \mathrm{~m}^{2}$ for each species. There is a significant linear relationship between rate of successful larval production and the speed with which the system approaches equilibrium, indicating the direct sensitivity of this space-limited ecosystem to colonization rates. 
Due to heavy (although possibly facultative) dependence of coral on its symbiotic photosynthetic algae (Muscatine and Porter, 1977), the linear growth rate of reef corals is closely related to ambient light levels. Eastern Pacific Pocillopora tissue, for instance, is about $15 \%$ plant biomass, $85 \%$ animal biomass by dry weight (L. Muscatine, personal communication, 1977), and its growth rate can vary by almost one order of magnitude under natural conditions (Glynn and Stewart, 1973). There is an inverse relationship between growth rate and depth, but the exact nature of this relationship has not yet been systematically investigated. Actual growth rates are usually lower than the maximum listed in Table I due to predation, competition, high turbidity or sedimentation. Additional simulations were therefore made using values ranging from one-tenth to ten times the original estimates of radial growth rate for each species. There is a significant linear relationship between growth rate and the speed with which equilibrium is reached, but this linear relationship is steeper than the one for increased larval production rates. A doubling of growth rates accelerates the approach to equilibrium more than does a doubling of successful larval production, reflecting the overriding importance of growth and competition after the initial colonization phase of coral community development.

To determine the impact of a single species' behavior on the behavior of the whole system, successful larval production and growth rates of species 1 and of species 6 were varied while holding the other parameters constant. Varying parameters for the least dominant, slowest-growing species (species 1 ) and for the most dominant, fastest-growing species (species 6) should indicate the extremes of system responses to a single species' behavior. Changing the rate of successful larval production for species 1 has no impact on the behavior of the system (Fig. 8, curve a), but the same change for species 6 has a marked effect on the speed with which equilibrium is reached (curve b). Similarly, changing the growth rate of species 1 has no impact, but changing the growth rate of species 6 has a marked effect. These results demonstrate that the behavior of the competitively dominant, fastest-growing species will dominate the behavior of the whole system in the absence of disturbance. This effect is fortunate from the standpoint of collecting field data, since it is often easier to make measurements on abundant and rapidly growing species in a community. Decreasing the rate of successful larval production (or growth) has a greater impact on the model response than a comparable increase (curve $b$ ) because the speed with which the equilibrium is reached approaches an upper bound.

\section{Growth rates and dominance}

The model can be used to explore the suggestion made by Porter (1974a) that a positive correlation between dominance and growth rate in eastern Pacific corals contributes to the rapid development of monospecific stands of the most dominant species. In contrast, among Caribbean species diges- 


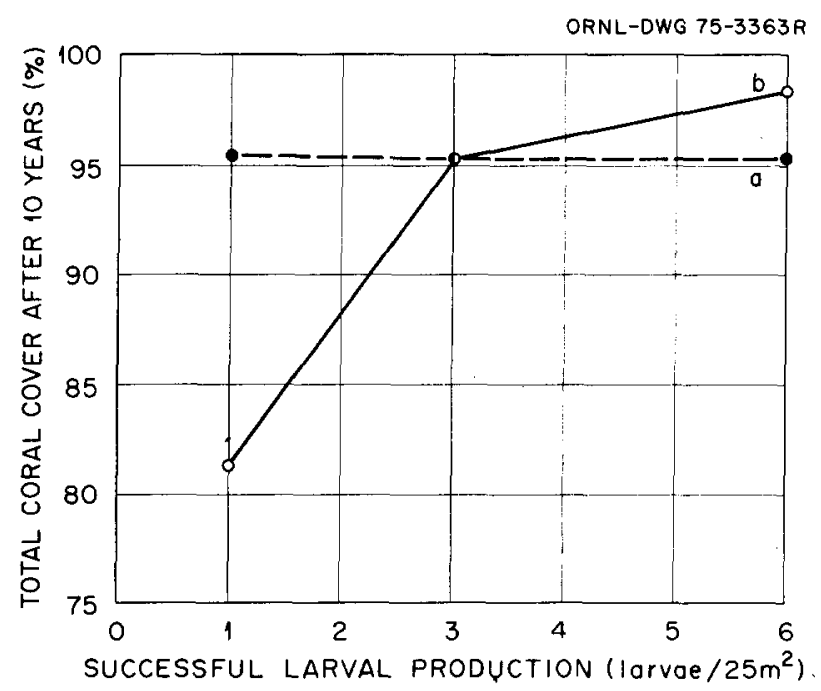

Fig. 8. Total coral cover after 10 years as a function of (a) successful larval production rate of species $1 ;(b)$ successful larval production rate of species 6 .

tively dominant corals are among the slowest-growing, retarding the development of a monospecific stand. For the six eastern Pacific coral species used in the model, rapid growth and dominance are positively correlated except that the third and fourth most dominant are the fourth and third fastest-growing, respectively. Four alternatives are tested: (A) the original assumption, a positive correlation between growth rate and dominance; (B) no correlation, all six species have growth rates equal to that of the fastest-growing species; (C) no correlation, all six species have growth rates equal to half the growth rates used in B; and (D) negative correlation between dominance and growth rate, i.e., species 1 (least dominant) is given the growth rate previously assigned to species 6 and vice versa, species 2 is given the growth rate previously assigned to species 5 , etc. Fig. 9 shows that the type of correlation between growth rate and dominance has a profound effect on the time required to reach equilibrium. Alternatives $\mathrm{C}$ and $\mathrm{D}$ are both significantly different from each other and from A and B. Reversing the correlation between growth rate and dominance from positive to negative extends the time to equilibrium by a factor of 10 . Although a monospecific stand of the most dominant species develops eventually if undisturbed, the time required (180-200 years) is so long that even infrequent reductions in coral cover (e.g., predation, storms) might prevent the community from ever reaching equilibrium.

These model experiments support the hypothesis that lack of correlation between growth rate and digestive dominance in Caribbean corals may be an important factor in maintaining the diversity of Caribbean coral communities. However, it cannot be the complete explanation. Additional factors - such as density dependence in growth or competitive dominance, or periodic removal 


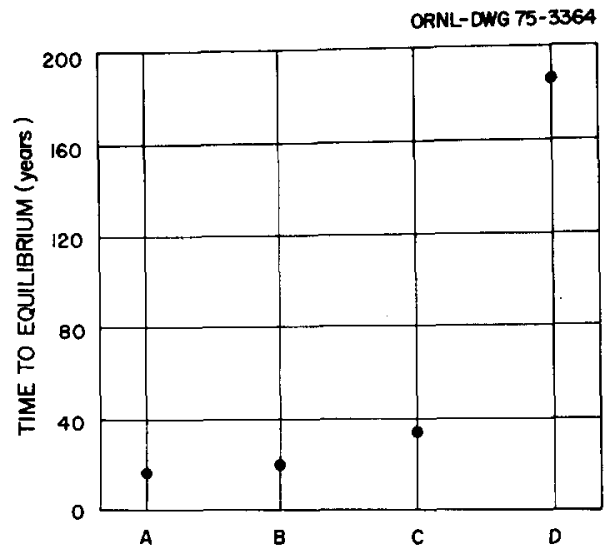

RELATIONSHIP BETWEEN DOMINANCE AND GROWTH RATE

Fig. 9. Time to equilibrium as a function of the relationship between growth rate and dominance: (A) positive correlation between growth rate and dominance; (B) no correlation, all growth rates equal to that of species $6 ;(C)$ no correlation, all growth rates equal half that in B: (D) negative correlation between growth rate and dominance.

of coral cover by predation or physical disturbance - must be acting to prevent the eventual development of a monospecific stand.

\section{Dominance versus growth rate as competitive strategies}

Porter (1974a) has suggested that there is an evolutionary trade-off between dominance and growth rate in the highly co-evolved Caribbean coral species, although this does not seem to be the case in geologically more recent eastern Pacific coral communities. (The slow-growing, less dominant species in the eastern Pacific may have broader physiological tolerances than faster-growing, more dominant species, and thus may not be less fit in all environments.) Runs of the model where growth rate and dominance are negatively correlated can be used to assess the competitive advantages of high competitive dominance versus rapid growth in different ecological situations. Fig. 10. shows the relative abundance of the six coral species as the plot develops toward a monospecific stand of species 6 for a model run with negative correlation between dominance and growth rates; compare this with Fig. $6 \mathrm{~b}$, where dominance and growth rate are positively correlated. In Fig. 6 the sequence in which the six species become more or less abundant through time shows that a fast growth rate (although low dominance), as exhibited by species 1 , is the most successful strategy during the first few years of community development or in ecological situations where frequent disturbance keeps the plot nearly empty most of the time. It may be considered an "r-type" strategy, in the sense of Southwood et al. (1974). Competitive dominance, even with a low growth rate, as exhibited by species 6 in this run of the model, is the most successful long-term strategy in situations 


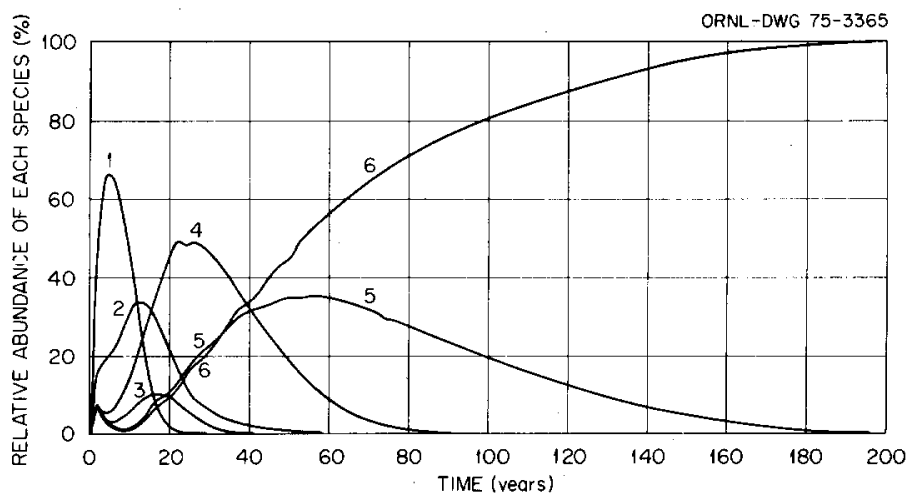

Fig. 10. Relative abundance of species 1 through 6 versus time for a model run in which dominance and growth rate are negatively correlated.

where the habitat remains undisturbed for long periods of time. This is a "K-type" strategy. In habitats that are disturbed with intermediate frequency, some combination of intermediate growth rate and intermediate dominance (species 2 or 4 ) will be most advantageous.

\section{Coral cover and diversity}

In all runs of the model except those where growth rate and dominance are negatively correlated, there is a monotonic increase in total coral cover (Fig. 6a) and a monotonic decrease in diversity (Fig. 6c) with time (year 2 is the first output from the model run). Thus there is always an inverse relationship between cover and diversity, as is observed on eastern Pacific (Porter, 1972a, 1974a) and Hawaiian (Grigg and Maragos, 1974) reefs. In those model runs where growth rate and dominance are negatively correlated, a positive relationship between cover and diversity persists for considerable periods of time. We believe this to be analogous to the positive relationship observed on some Caribbean reefs (Porter, 1972b, 1974a). These results strengthen the hypothesis that the balance between dominance and growth rate in Caribbean coral species is important in determining the structure of Caribbean coral communities.

The role of periodic disturbances, in combination with growth and dominance relationships, in maintaining diversity should be investigated further. The frequency of storms of different intensities in a given locality is largely unknown. Stoddart $(1971,1972)$ suggests that the frequency of catastrophic disturbances in an area correlates with the presence of certain shallow water formations and their orientation, but systematic observations are lacking.

\section{DISCUSSION}

The major processes of coral community development - radial growth rate, competition by overtopping or extracoelenteric digestion, and mortal- 
ity due to disturbance - appear to be continuous in time and space and should be appropriately modeled by a system of differential equations. We have made several unsuccessful attempts to describe this system in terms of the continuous rates of change in area covered by each species with no explicit spatial variables. The interaction terms - describing the area a species gains by growing over less dominant species and loses by being grown over by more dominant species - are particularly troublesome because the frequency and outcome of competitive interactions depend on the spatial configuration of corals in the plot. For example, since competitive interactions take place only at the colony perimeter, a species will have more interactions if it has many small colonies distributed throughout the plot than if it has only one large colony. The behavior shown in Fig. $6 \mathrm{~b}$ and Fig. 10 looks like the solution to a set of rather simple differential equations, but, as mentioned above, we could not derive a set of simple equations from basic biological information. At best, we could fit a set of equations to the curves in Fig. 6b and Fig. 10, but the parameters had no obvious biological meaning, did not satisfy the boundary conditions, and could not easily be changed to incorporate alternative hypotheses. The model described in this paper seems to be the simplest and most flexible representation of the biological system.

In developing the simulation model, we made discrete approximations of continuous temporal and spatial processes that may seem crude. Yet the discrete spatial model (based on a few simple assumptions about coral growth and competition) generates a realistic description of coral community development in undisturbed eastern Pacific reefs. It has provided a framework for testing effects of different reproductive, growth, and competitive strategies on community patterns. We have used the model to corroborate Porter's (1974a) hypothesis that the type of correlation between competitive dominance and growth rate could be partly responsible for the different coral cover and diversity relationships observed on some Caribbean and eastern Pacific reefs. The model also suggests the need for more studies on the role of periodic disturbances in maintaining reef community structure. Although we have found our two-dimensional approximation of coral colony structure to be a very useful tool for investigating coral reef development, further realism could be gained by extending the model into a third spatial dimension in order to study the vertical structure of coral reefs.

We plan to use the model to investigate other features of coral ecology. It can be used to explore effects of differences in dispersal and colonizing ability among different species. For example, Grigg and Maragos (1974) note that on Hawaiian reefs recovering from lava inundation, larvae of certain coral species do not appear for some years, until the substrate has been stabil. ized by early colonizers. Various non-random dispersal and colonization patterns could be studied, such as the possibility that colonization is heavier near the parent coral (Lewis, 1974)

The effects of recurring physical disturbances - waves, hurricanes, lava 
flows, freshwater inundation or man-induced perturbations such as oil spills - could be simulated using a stochastic model to generate disturbances. The frequency and severity of the disturbance and differential mortality for different species, depending on growth form (e.g. branching versus spherical) and physiological tolerance, would influence community development (Connell, 1973; Loya, 1976). The level and frequency of disturbance required to maintain observed patterns of diversity could then be investigated.

Biological disturbance, such as predation by the crown-of-thorns starfish, could be modeled as selective or random removal of coral cover from areas in the plot. Data on the effects of predation on coral community structure are becoming available for the eastern Pacific (Porter, 1972a; Glynn, 1973), Hawaii (Branham et al., 1971), Guam (Randall, 1973), Australia (Pearson, 1974) and the Red Sea (Loya, 1976). Species assemblages from different geographical areas for which growth and competition data are available could be modeled. The types and intensity of factors producing observed differences in community characteristics could be analyzed by comparing model behavior with field data. In general, in all cases where the spatially dominant coral (in the eastern Pacific ecosystem, Pocillopora) sustains disproportionately high destruction through biological disturbances such as predation or localized competitive inferiority, or from physical disturbances such as storm damage, the diversity of the system will be increased and the trend towards species loss will be retarded (Paine, 1966; Porter, 1974a).

The model also has potential use as a tool for designing and evaluating field experiments. The grid patterns produced by simulations can be sampled using different field sampling methods (e.g., transect, quadrat) and their accuracy and precision in estimating cover and diversity evaluated for a wide variety of community patterns. Field experiments involving manipulation of natural communities could first be simulated to suggest the range of experimental treatments that should be used.

Several other investigators have developed models similar to the coral model described here. Glass (1973) has developed models for the dynamics of inhibitory fields in one dimension. The process is similar to the growth and interaction of coral colonies, but his model does not include space explicitly. Levin and Paine (1974) have studied the role of disturbance and patch formation in determining community structure. Their model deals with a problem related to coral spatial patterns, but on a larger scale, since they do not consider overlap or confrontation between patches. Williams and Mitton (1973) and Williams (1975) have constructed two-dimensional pencil-andpaper simulations of competition between sexually and asexually reproducing clones that are conceptually very similar to the computer simulations described in this paper; Korn (1969) has also developed a pencil-and-paper model for simulating the growth of a colonial alga on a planar lattice of points.

The model described here was motivated by an interest in coral commun- 
ity dynamics, but its application is certainly not limited to this topic. It could be used advantageously to study the dynamics of many systems of relatively immobile organisms - benthic invertebrates, such as barnacles and sponges; bacterial colonies; mosses, algae, lichens, and higher plants (Harper and White, 1971) - where spatial pattern is important in determining the frequency and type of biological interactions.

\section{SUMMARY}

This paper describes a discrete spatial simulation model of coral community development based on larval production, radial growth, and interspecific competition. The model is quantified using data for six eastern Pacific coral species, and realistically simulates the development of undisturbed reefs into a monospecific stand of the competitively most dominant species. Analyses of some technical aspects of the model show that the results are not sensitive to changes in time-step length, the distance between grid points in the simulated plot, or the order in which larvae from each species settle in the plot.

The model investigates some of the factors influencing coral community structure. Results suggest that coral reproduction by means of planktonic larvae is important mainly during the early stages of community development when the reef area is relatively bare. Within 8 to 10 years the plot is $90 \%$ covered by coral, and growth rates and competitive interactions of established coral colonies dominate the behavior of the system. Simulation results support Porter's (1974a) hypothesis that a positive correlation between growth rate and dominance in eastern Pacific coral species could accelerate the development of a monospecific stand of the dominant, fastestgrowing species. The lack of correlation between digestive dominance and growth rate in Caribbean coral species, in conjunction with occasional physical disturbance such as hurricanes, may maintain high diversity in Caribbean reef communities. The model shows that a fast growth rate is a more successful competitive strategy than high dominance in the early stages of community development, or in situations where coral cover is kept low by frequent physical or biological disturbance. High dominance is the more successful strategy for space capture and retention over the long term in environments where coral cover remains undisturbed.

Although the discrete spatial model is only an approximation to continuous processes, it is a more flexible and biologically meaningful representation of the real system than any differential equation formulations we have tried. The model shares similarities with other models that have been developed to study inhibitory fields, growth of colonial algae, patch formation in benthic communities, and competition between sexual and asexual propagules.

Although the model was developed to study coral community dynamics, it is well suited to study any relatively immobile organisms where spatial pattern has an important influence on system dynamics. 


\section{ACKNOWLEDGMENTS}

We would like to thank R.L. Patterson, S.P. Hubbell, P.W. Glynn, and members of the Oak Ridge Systems Ecology Group for their helpful conversations and suggestions.

\section{REFERENCES}

Barnes, D.J., 1973. Growth in colonial scleractinians. Bull. Mar. Sci., 23: 280-298. Branham, J.M., Reed, S.A., Bailey, J.H. and Caperon, J., 1971. Coral-eating sea stars Acanthaster planci in Hawaii. Science, 172: 1155-1157.

Connell, J.H., 1971. On the role of natural enemies in preventing competitive exclusion in some marine animals and in rainforest trees. Proc. Adv. Study Inst. Dynamics Numbers Popul. (Oosterbeek, 1970), pp. 298-312.

Connell, J.H., 1973. Population ecology of reef-building corals. In: O.A. Jones and R. Endean (Editors), Biology and Geology of Coral Reefs, Vol. 2. Academic Press, New York, N.Y., pp. 204-245.

Dayton, P.K., 1971. Competition, disturbance, and community organization: The provision and subsequent utilization of space in a rocky intertidal community. Ecol. Monogr., $41: 351-389$.

Dayton, P.K. and Hessler, R.R., 1972. Role of biological disturbance in maintaining diversity in the deep sea. Deep Sea Res., 19:199-208.

Endean, R., 1973. Population explosion of Acanthaster planci and associated destruction of hermatypic corals in the Indo-West Pacific region. In: O.A. Jones and R. Endean (Editors), Biology and Geology of Coral Reefs, Vol. 2. Academic Press, New York, N.Y., pp. 389-438.

Glass, L., 1973. Stochastic generation of regular distributions. Science, 180: 1061-1063.

Glynn, P.W., 1973. Acanthaster: Effect on coral reef in Panama. Science, 180: 504-506.

Glynn, P.W., 1974. Rolling stones among the scleractinians. Proc. 2nd Int. Coral Reef Symp., 2: 183-198.

Glynn, P.W. and Stewart, R.H., 1973. Distribution of coral reefs in the Pearl Islands (Gulf of Panama) in relation to thermal conditions. Limnol. Oceanogr., 18: 367-379.

Glynn, P.W., Stewart, R.H. and McCosker, J.E., 1972. Pacific coral reefs of Panama: Structure, distribution and predators. Geol. Rundschau, 61:598-626.

Grassle, J.F. and Grassle, J.P., 1974, Opportunistic life histories and genetic systems in marine benthic polychaetes. J. Mar. Res., 32: 253-284.

Grassle, J.F. and Sanders, H.L., 1973. Life histories and the role of disturbance. Deep Sea Res., 20:643-659.

Grigg, R.W. and Maragos, J.R., 1974. Recolonization of hermatypic corals on submerged lava flows in Hawaii. Ecology, 55: 387-395.

Harper, J.L. and White, J., 1971. The dynamics of plant populations. Proc. Adv. Study Inst. Dynamics Numbers Popul. (Oosterbeek, 1970), pp. 41-63.

Harrigan, J.F., 1972. The Planula Larva of Pocillopora damicornis: Lunar Periodicity of Swarming and Substratum Selective Behaviour. Thesis, Univ. of Hawaii, Honolulu, Hawaii, 213 pp.

Hunter, J.S. and Naylor, T.H., 1970. Experimental designs for computer simulation experiments. Manage. Sci., 16: 422-434.

Janzen, D.H., 1971. Seed predation by animals. Annu. Rev. Ecol. Syst., 2: 465-492.

Korn, R.W., 1969. A stochastic approach to the development of Coleocheate. J. Theor. Biol., 24: 147-158.

Lang, J.C., 1973. Interspecific aggression by scleractinian corals. 2 . Why the race is not only to the swift. Bull. Mar. Sci., 23. 260-279. 
Levin, S.A. and Paine, R.T., 1974. Disturbance, patch formation, and community structure. Proc. Natl Acad. Sci., U.S.A., 71: 2744-2747.

Levinton, J.S., 1970. The paleoecological significance of opportunistic species. Lethaia, 3: 69-78.

Lewis, J.B., 1974. The settlement behavior of planula larvae of the hermatypic coral Favia fragum (Esper). J. Exp. Mar. Biol. Ecol., 15: 165-172.

Loya, Y., 1976. Recolonization of Red Sea corals as affected by natural catastrophies and man-made perturbations. Ecology, 57: 278-289.

Muscatine, L. and Porter, J.W., 1977. Reef corals: Mutualistic symbioses adapted to nutrient-poor environments. Bioscience, $27: 454-460$.

Paine, R.T., 1966. Food web complexity and species diversity. Am. Nat., 100: 65-75.

Pearson, R.G., 1974. Recolonization by hermatypic corals on reefs damaged by Acanthaster. Proc. 2nd Int. Coral Reef Symp., 2: 207-215.

Pielou, E.C., 1966. The measurement of diversity in different types of biological collections. J. Theor. Biol., 13: 131-144.

Porter, J.W., 1972a. Predation by Acanthaster and its effect on coral species diversity. Am. Nat., 106: 487-492.

Porter, J.W., 1972b. Patterns of species diversity in Caribbean reef corals. Ecology, 53: $744-748$.

Porter, J.W., 1974a. Community structure of coral reefs on opposite sides of the Isthmus of Panama. Science, 186: 543-545.

Porter, J.W., 1974b. Zooplankton feeding by the Caribbean reef-building coral Montastrea cavernosa. Proc. 2nd Int. Coral Reef Symp., 1: 111-125.

Randall, R.H., 1973. Coral reef recovery following extensive damage by the "crown-ofthorns" starfish, Acanthaster planci (L). Publ. Seto Mar. Biol. Lab., 20: 469-489.

Reiswig, H.M., 1973. Population dynamics of three Jamaican Demospongiae. Bull. Mar. Sci., 23: 191-226.

Rhoads, D.C., 1973. The influence of deposit-feeding benthos on water turbidity and nutrient recycling. Am. J. Sci., 273: 1-22.

Ross, M.A. and Harper, J.L., 1972. Occupation of biological space during seedling establisment. J. Ecol., 58: 467-485.

Schuhmacher, H., 1974. On the conditions accompanying the first settlement of corals on artificial reefs with special reference to the influence of grazing sea urchins (Eilat, Red Sea). Proc. 2nd Int. Coral Reef Symp., 1: 257-267.

South wood, T.R.E., May, R.M., Hassell, M.P. and Conway, G.R., 1974. Ecological strategies and population parameters. Am. Nat. 108: 791-804.

Steele, R.G.D. and Torrie, J.H., 1960. Principles and Procedures of Statistics, with Special Reference to the Biological Sciences. McGraw-Hill, New York N.Y., 481 pp.

Stimson, J., 1974. An analysis of the pattern of dispersion of the hermatypic coral Pocillopora meandrina var, nobilis Verrill. Ecology, 55: 445-449.

Stoddart, D.R., 1969. Ecology and morphology of recent coral reefs. Biol. Rev., 44: $433-498$.

Stoddart, D.R., 1971. Coral reefs and islands and catastrophic storms. In: J.A. Steers (Editor), Applied Coastal Geomorphology. MacMillan, London, pp, 155-194.

Stoddart, D.R., 1972. Regional variation in Indian Ocean coral reefs. Mar. Biol. Assoc. India, Proc. Symp. Corals and Coral Reefs, 1969: 155-174.

Sutherland, J.P., 1974. Multiple stable points in natural communities. Am. Nat., 108: $859-873$.

Williams, G.C., 1975. Sex and Evolution. Princeton University Press, Princeton, N.J., 200 pp.

Williams, G.C. and Mitton, J.B., 1973. Why reproduce sexually? J. Theor. Biol., 39: 545554. 